\title{
PRECOCIOUS MENSTRUATION IN HYPOTHYROIDISM
}

\author{
BY \\ H. H. VAN GELDEREN \\ From the University Children's Department, Leiden, and the Dr. Mr. Willem van den Bergh Stichting, \\ Noordwijk
}

(RECEIVED FOR PUBLICATION NOVEMBER 13, 1961)

In children with untreated hypothyroidism puberty is usually late. Signs of precocious puberty are rare and present an interesting problem. We describe a girl with congenital hypothyroidism and precocious menstruation, who was followed up for a long period.

\section{Case Report}

C.v.B. is a girl who was born of psychopathic criminal and, in all probability, mentally subnormal parents. Her mental and physical development was backward from birth; at the age of 4 she could walk but did not speak. Earlier data are lacking. She stayed in several children's homes, and from the age of 9 she was in the Institution for Mentally Deficient Children in Noordwijk. At the age of $11 \frac{3}{4}$ years she was admitted to the University Gynaecological Department because of torsion of a cystic ovary, and an operation was performed, (Prof. Holmer). The consulting paediatrician (Dr. Havekamp Begemann) made a diagnosis of congenital hypothyroidism, and she was admitted to the Children's Department. She showed typical signs of cretinism (Fig. 1), and further investigations confirmed the diagnosis of athyrosis (Table). There was dwarfism, a low temperature and pulse rate, constipation, extreme slowness, and an I.Q. of 57. Secondary sexual characteristics were absent apart from a slight swelling of the breasts. The sella turcica was too large (Fig. 2).

From the age of 6 the patient had had regular uterine bleedings, lasting for a few days, often with some abdominal pain. The frequency was once in two to six weeks. From 9-11 $\frac{1}{2}$ years the bleedings stopped, but thereafter they recurred again. Gynaecological examination and laparotomy at $11 \frac{3}{4}$ years demonstrated a uterus of adult size and cystic ovaries; the left one was twisted and ruptured. Pathological examination of the left ovary and part of the right one showed multiple follicular cysts and only a few primordial follicles.

TABLE

\begin{tabular}{|c|c|c|c|c|c|c|c|}
\hline & & \multicolumn{5}{|c|}{ Cases } & \multirow{3}{*}{ This Case } \\
\hline & & \multirow{2}{*}{$\begin{array}{l}\text { Silver } \\
(1958)\end{array}$} & \multirow{2}{*}{$\begin{array}{c}\text { Bergstrand } \\
(1955)\end{array}$} & \multicolumn{3}{|c|}{ Van Wyk and Grumbach (1960) } & \\
\hline & & & & 1 & 2 & 3 & \\
\hline 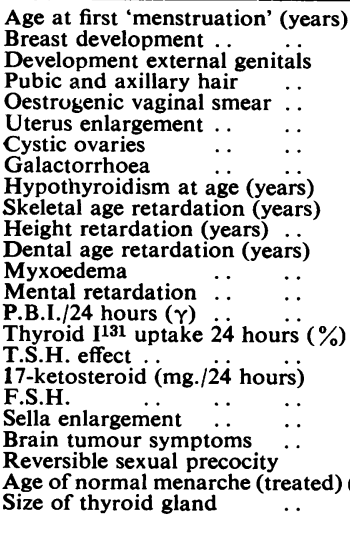 & 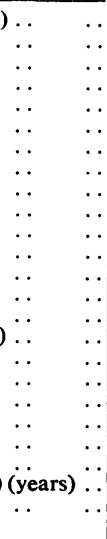 & $\begin{array}{c}7 \\
\pm \\
\pm \\
+ \\
+ \\
\pm \\
+ \\
-1 \\
\pm \\
0 \cdot 5 \text { (B.E.I.)* } \\
- \\
2 \cdot 1 \\
+ \\
- \\
+ \\
\text { Normal }\end{array}$ & $\begin{array}{c}9 \\
\pm \\
- \\
+ \\
- \\
0 \\
-1 \frac{1}{2} \\
-1 \\
+ \\
\text { I.Q. } \\
4 \cdot 4(!) \\
16 \cdot 1 \\
-- \\
\text { Normal } \\
- \\
+ \\
\frac{+}{15} \\
\text { Normal }\end{array}$ & $\begin{array}{l}8 \frac{1}{2} \\
+ \\
+ \\
+ \\
+ \\
\frac{1}{+} \\
7 ? \\
-2 \frac{1}{2} \\
-1 \frac{1}{2} \\
-1 \frac{1}{2} \\
+ \\
0 \cdot \\
0 \cdot 8 \\
\text { Small } \\
-\cdot \\
2 \cdot 1 \\
- \\
+ \\
\frac{+}{+} \\
12 \\
\text { Normal }\end{array}$ & $\begin{array}{c}11_{3}^{2} \\
+ \\
+ \\
+ \\
+ \\
+ \\
- \\
+ \\
\text { c. } 8 \\
-43 \\
-4 \\
+ \\
1 \cdot 8 \\
6 \\
- \\
1 \cdot 7 \\
- \\
+ \\
\pm \\
+ \\
13 \frac{1}{2} \\
\text { Hashimoto } \\
\text { struma }\end{array}$ & $\begin{array}{c}7 \\
+ \\
+ \\
+ \\
+ \\
+ \\
5 \\
-1 \frac{1}{3} \\
0 \\
0 \\
+ \\
2 \cdot 4 \\
15 \\
- \\
2 \cdot 2 \\
- \\
+ \\
+ \\
+ \\
\text { Small }\end{array}$ & $\begin{array}{c}6 \\
\pm \\
- \\
+ \\
+ \\
\pm \\
\pm \\
0 \\
-5 \\
-6 \frac{1}{2} \\
-6 \\
+ \\
\text { I.Q. } 53 \\
1 \cdot 4 \\
2 \\
0 \cdot 8 \\
+ \\
\pm \\
\pm \\
+ \\
14 \\
\text { Not palpable }\end{array}$ \\
\hline
\end{tabular}

* Butanol extractable iodine. 


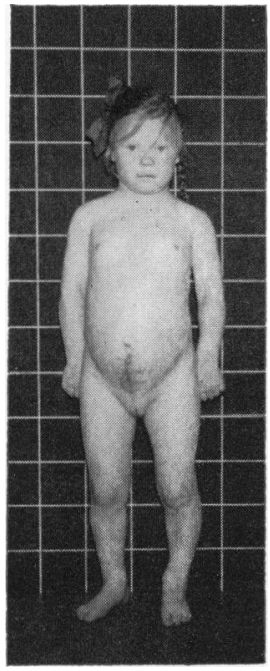

FIG. 1.-Patient at the age of 11 years showing typical signs of cretinism.

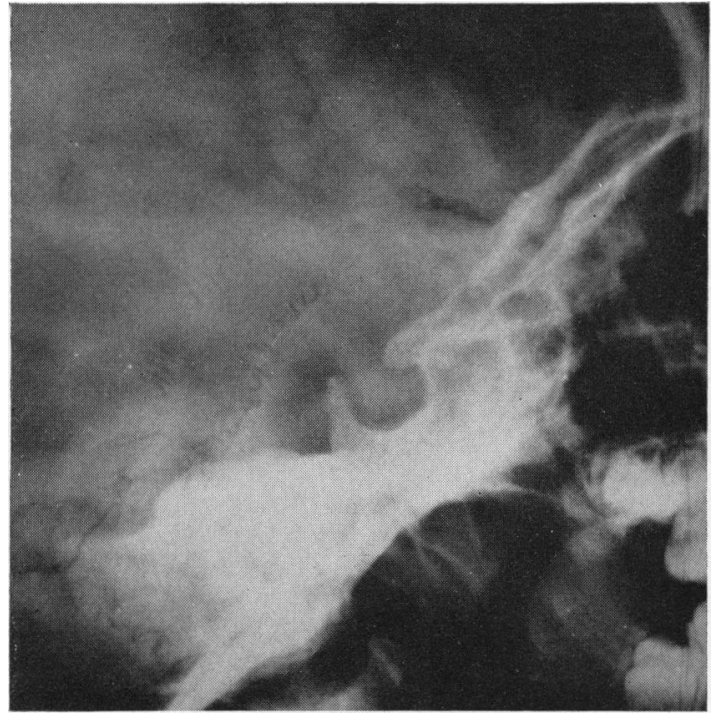

FIG. 2.-Radiograph showing enlarged sella turcica before treatment.

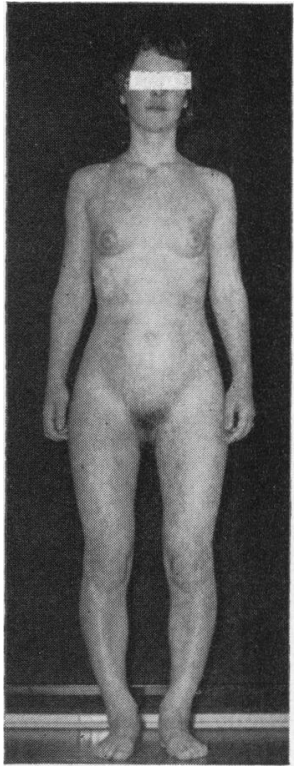

FIG. 3.-Patient at age of 18 years after six years of treatment with thyroxin.
Uterine endometrium biopsy was indicative of glandular and interstitial hyperplasia. Menstruation occurred again after operation, but stopped completely after thyroid therapy had been started. At the age of $14 \frac{1}{2}$ normal regular menstruation began again, together with all the other signs of puberty.

Thyroid therapy encouraged physical development, and the patient, now at 18 years of age, is a rather small but well-developed girl, bright and active enough to be a useful household help and ready to leave the Institution (Figs. 3 and 4). Radiographs of the skull show that the sella is the same size as at the age of $11 \frac{3}{4}$ years and is therefore normal for her present age.

\section{Discussion}

The patient showed the classical picture of congenital athyrosis, but with precocious menstruation from the age of 6 years and with metropathia haemorrhagica at the age of 11 years. The precocious oestrogenic activity had not given rise to other signs of precocious puberty outside the genitals; skeletal age, however, did not lag behind height age.

At the time the patient was studied in the Children's Department no explanation could be found for the precocious menstruation. No comparable patients had been reported, apart from a short article by Kendle (1905). In the past few years, however, five girls with symptoms similar to our patient, some of them also with galactorrhoea, were described by Silver (1958), Bergstrand (1955) and van Wyk and Grumbach (1960). All patients showed precocious menstruation which stopped as soon as thyroid therapy was started. The main symptoms are summarized in the Table.

At first explanation was difficult. Primary hypophyseal or hypothalamic disturbance with secondary hypothyroidism and gonadotropic activity was excluded by the lack of effect of thyroid stimulating hormone (T.S.H.) on thyroid function and by cessation of menstruation after thyroid therapy. A slowing down of catabolism of sexual hormones does not explain the precocity. In adults with acquired myxoedema, metropathia haemorrhagica is not unusual (Paschkis, Rakoff and Cantarow, 1958).

An attractive theory is offered by van Wyk and Grumbach (1960). They consider that the hypothyroidism leads to enhanced hypophyseal production not only of thyrotropic hormone, but in some cases of gonadotropic and lactogenic hormones, i.e. an 'overlap' of the hypophyseal stimulation caused by the low or absent thyroid activity. The authors point to analogous situations such as galactorrhoea after adrenalectomy, high T.S.H. production in some cases of hypogonadism, metropathia haemorrhagica in acquired adult myxoedema, possibly gynaecomastia in Klinefelter's syndrome 


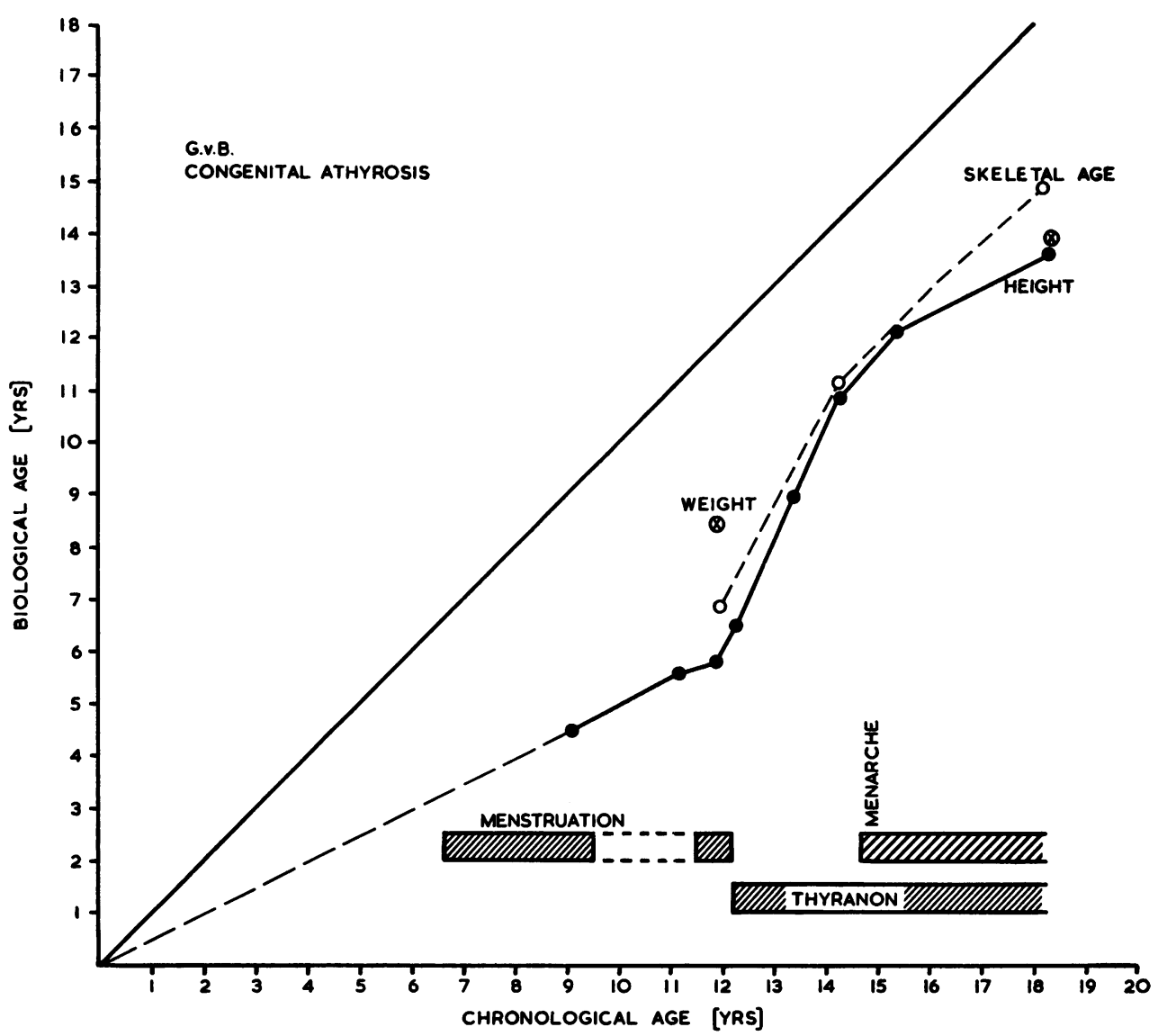

FIG. 4.-Chart showing skeletal age plotted against chronological and biological age.

and pigmentation in Addison's disease (though distinction between A.C.T.H. and melanophor stimulating hormone (M.S.H.) is uncertain). They also recall animal experiments in which a 'feed-back overlap' may be present.

In our patient gonadotropins were demonstrated in the urine; however, the results of the method used may have been influenced by high oestrogen production. The cessation of all signs of oestrogen activity after thyroid therapy fits in well with the theory of 'feed-back overlap'.

\section{Summary}

A short description is given of a girl with hypothyroidism, precocious menstruation and metropathia haemorrhagica. After thyroid therapy menstruation stopped immediately; at the age of 14 normal puberty occurred. Findings in the literature of five other patients with the same syndrome are summarized.

The explanation offered by van Wyk and Grumbach is mentioned: hypothyroidism results in stimulation of thyrotropic activity with overlap to gonadotropic activity. Though this theory has not yet been proved conclusively, the characteristics of the syndrome fit in well with it.

\section{REFERENCES}

Bergstrand, C. G. (1955). A case of hypothyroidism with signs of precocious sexual development. Acta endocr., $20,338$.

Kendle, F. W. (1905). Case of precocious puberty in a female cretin. Brit. med. J., 1, 246.

Paschkis, K. E., Rakoff, A. E. and Cantarow, A. (1958). Clinical Endocrinology, 2nd ed. Hoeber, New York.

Silver, H. K. (1958). Juvenile hypothyroidism with precocious sexual development. J. clin. Endocr., 18, 886.

van Wyk, J. J. and Grumbach, M. M. (1960). Syndrome of precocious menstruation and galactorrhea in juvenile hypo. thyroidism. J. Pediat., 57, 416. 